\title{
Selective laser melting process optimization of Ti-Mo-TiC metal matrix composites
}

\author{
Bey Vranckena,b, Sasan Dadbakhshc,d, Raya Mertensc , Kim Vanmeensela, Jef Vleugelsa, Shoufeng Yangc, Jean- \\ Pierre Kruth (1) c
}

${ }^{a}$ Department of Materials Engineering, KU Leuven, Leuven, Belgium

${ }^{b}$ Lawrence Livermore National Laboratory, Livermore, California, United States

c PMA, Department of Mechanical Engineering, KU Leuven, Member of Flanders Make, Leuven, Belgium

${ }^{d}$ Department of Production Engineering, KTH Royal Institute of Technology, Stockholm, Sweden

Selective Laser Melting (SLM) was used to process a powder mixture of CP Ti, $6.5 \mathrm{wt} \% \mathrm{Mo}$ and $3.5 \mathrm{wt} \% \mathrm{Mo}_{2} \mathrm{C}$. The process parameters were optimized to obtain full-density, crack free parts. After the in situ decomposition of $\mathrm{Mo}_{2} \mathrm{C}$ in favor of the formation of TiC, the material consisted of a homogeneous dispersion of submicrometer sized TiC platelets in a $\beta$-(Ti,Mo) matrix exhibiting a high hardness up to $550 \mathrm{HV}$ and compressive yield stress of $1164 \pm 37$ MPa. The microstructure and mechanical properties could be tailored by variation of the process parameters within the high-density processing window, as well as through post-process heat treatments.

Selective Laser Melting (SLM), Metal matrix composite, Titanium

\section{Introduction}

Additive manufacturing (AM) is enabling production of geometrically complex parts that reduce weight, increase productivity, and improve performance. AM has also generated a new path to create novel materials. In Selective Laser Melting (SLM) for example, the powder-based production, localized melting, and high cooling rates are particularly suitable conditions to create homogeneously dispersed metal matrix composites (MMCs) [1]. The small melt pool locally mixes the constituents, rapidly solidifies and limits segregation to the micro-scale if it even occurs at all. The Marangoni flow inside the melt pool provides efficient mixing, and high cooling rates avoid coarsening of the formed secondary phase particles [2]. The in situ reaction leads to a strong interface between the matrix and reinforcing particles [3]. Additionally, supersaturation of alloying elements in the matrix can cause particles to precipitate in the heat-affected zone during deposition of subseq layers or during post-process heat treatment.

In situ alloying during SLM is receiving an increasing amount of attention with the intent to facilitate processing of a material, and/or to induce superior properties. Specifically for Ti-based alloys, Ti6Al4V has been processed from an elemental mixture of $\mathrm{Ti}, \mathrm{Al}$ and V [4]. Addition of various amounts of Mo to Ti during Directed Energy Deposition (DED) demonstrated that a $100 \% \beta$ phase can be maintained at to room temperature upon quenching with $10 \mathrm{wt} \%$ Mo [5]. This suppresses the reaction to the hard but less ductile $\alpha^{\prime}$ martensite. Consequently, SLM of Ti6Al4V+10Mo resulted in a metastable, fully $\beta$ phase alloy of which the ductility greatly surpassed SLM'ed Ti6Al4V (20\% versus $8 \%$ [6]), while the strength was higher than that of other $\beta$-Ti phase alloys with comparable ductility [7].

D. Gu et al. have performed extensive research on the AM production of MMCs, including $\mathrm{Ti}$ matrices $[2,8]$, or $\mathrm{TiC}$ reinforcements [2,9]. A maximum hardness of $570 \mathrm{HV}$ was achieved when mixing $12.5 \mathrm{wt} \%$ spherical nanosized TiC powder with larger Ti powder, creating a dense dispersion of nano-sized platelet $\mathrm{TiC}$ precipitates [2]. Similar $\mathrm{TiC}$ platelets were also reported to form during DED of TiC and the TA15 Ti alloy, with the platelets said to originate from the eutectic reaction, while primary TiC was rounder in shape [10]. The mechanical properties deteriorated for TiC additions in excess of $5 \mathrm{wt} \%$. The size of the TiC formed during DED of a Ti6Al4V + TiC mixture could be controlled by variation of the deposition parameters [11].

In this work, the powder mixture consisted of $6.5 \mathrm{wt} \%$ Mo, 3.5 ${ }_{w t} \% \mathrm{Mo}_{2} \mathrm{C}$, and remainder Grade $1 \mathrm{Cp} \mathrm{Ti}$. Fully dissolved, the 3.5 $\mathrm{wt} \% \mathrm{Mo}_{2} \mathrm{C}$ theoretically results in $1 \mathrm{wt} \%$ of reinforcing $\mathrm{TiC}$ particles. An additional $6.5 \mathrm{wt} \%$ Mo was added for a total of 10 $\mathrm{wt} \%$ Mo in the final alloy, previously stated to be sufficient to suppress $\alpha^{\prime}$ formation and stabilize the $\beta$ phase [5]. Since TiC was expected to embrittle the material, the intention was to use the more ductile Mo-induced $\beta$ phase to facilitate SLM processing, with the possibility for further optimization through post-process heat treatments. This work shows that the extent of the $\mathrm{Ti}+\mathrm{Mo}+\mathrm{Mo}_{2} \mathrm{C}$ $\rightarrow \beta-(\mathrm{Ti}, \mathrm{Mo})+\mathrm{TiC}$ reaction depends on the SLM process parameters as well as the heat treating regime.

\section{Materials \& Methods}

\subsection{Material and SLM processing}

Grade 1 CP Ti powder (LPW Technology, UK) with a particle size between 15-45 $\mu \mathrm{m}$ was dry mixed for 8 hours in a Turbula mixer with $6.5 \mathrm{wt} \%$ Mo (particle size 3-5 $\mu \mathrm{m}$ ) and $3.5 \mathrm{wt} \% \mathrm{Mo}_{2} \mathrm{C}$ (Changsha Langfeng Metal Materials Co. Ltd., China, particle size 3$5 \mu \mathrm{m}$ ). Figure 1 shows the resulting powder mixture, where the smaller irregular shaped $\mathrm{Mo}$ and $\mathrm{Mo}_{2} \mathrm{C}$ particles (white particles) partially decorate the larger spherical Ti particles (grey), though a majority does not adhere to the Ti as would be desired. This is likely due to the large size of the $\mathrm{Mo}$ and $\mathrm{Mo}_{2} \mathrm{C}$ powder. Furthermore, hard $\mathrm{Mo}$ or $\mathrm{Mo}_{2} \mathrm{C}$ starting powder agglomerates were still present that were not de-agglomerated during mixing.

The in-house developed LM-Q SLM machine (PMA, M.E. Dept., KU Leuven) was used to produce $10 \times 10 \times 7.5 \mathrm{~mm}^{3}$ cuboids in an $\mathrm{Ar}$ atmosphere containing less than $50 \mathrm{ppm} \mathrm{O}_{2}$. The laser spot size was $60 \mu \mathrm{m}\left(1 / e^{2}\right)$. The system is described in detail in [12]. The zigzag scan strategy was rotated $90^{\circ}$ between each layer. A wide range of SLM process parameters were employed, varying the laser power $P$ between $40-450 \mathrm{~W}$, the scan speed $v$ between 200 $-2000 \mathrm{~mm} / \mathrm{s}$, the hatch spacing $h$ between $35-100 \mu \mathrm{m}$ and a layer thickness $t$ of either 30 or $60 \mu \mathrm{m}$. This resulted in an energy density $E=P /(v . h . t)$ between $40-320 \mathrm{~J} / \mathrm{mm}^{3}$. All employed parameter sets are shown in Fig. 2. Some parameter sets are marked in red, indicating that they were unstable and terminated before build completion. For clarity, the discussion will focus on density and microstructure trends visible over these ranges. All heat treatment and mechanical property-related results in Fig. 5-7 were obtained on samples built with $P=235 \mathrm{~W}, v=1400 \mathrm{~mm} / \mathrm{s}, h=70$ $\mu \mathrm{m}$ and $t=30 \mu \mathrm{m}$ (sample 2L in Fig 3(b)). 


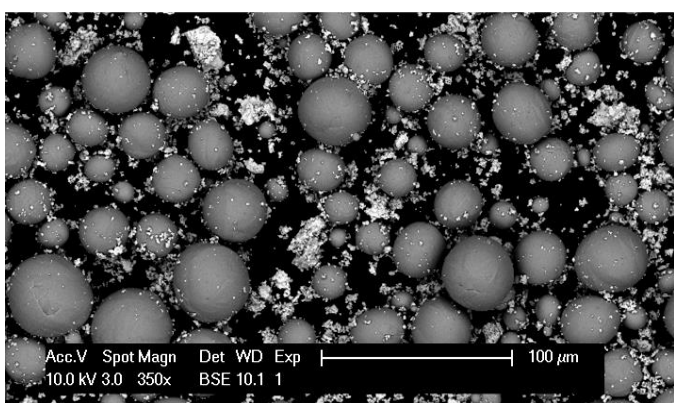

Figure 1. Powder mixture of Grade $1 \mathrm{CP}$ Ti (grey spherical particles), 6.5 wt $\%$ Mo (white) and $3 \mathrm{wt} \% \mathrm{Mo}_{2} \mathrm{C}$ (white)

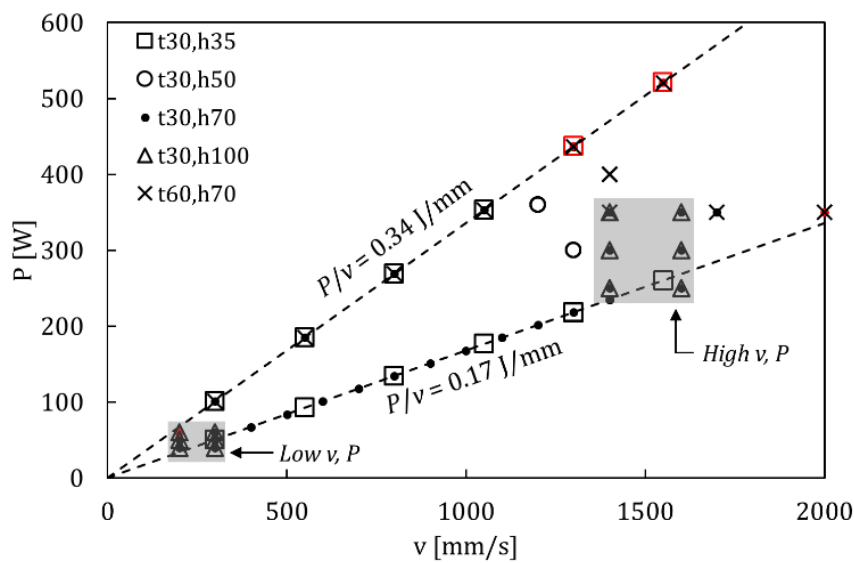

Figure 2. Process parameters used in this work, including two different low and high laser power/scan speed regions. Further parameter sets are mostly located along two different iso- $\mathrm{P} / \mathrm{v}$ ratio curves.

\subsection{Characterization}

Heat treatments were performed in a vertical tube furnace for 1 hour in an $\operatorname{Ar}$ (3 ppm oxygen) atmosphere. Air cooling was applied after aging $\left(400^{\circ} \mathrm{C}-600^{\circ} \mathrm{C}\right)$, and water quenching after annealing $\left(750^{\circ} \mathrm{C}-850^{\circ} \mathrm{C}\right)$. Microstructural characterization was carried out using a FEI XL30 FEG scanning electron microscope (SEM). Only SEM BSE contrast imaging was employed on non-etched specimens to reveal microstructural features. Phase identification was carried out using a Siemens D500 diffractometer with $\mathrm{Cu} \mathrm{K}_{\alpha}$ radiation $(\lambda=1.54184 \AA)$. MicroVickers hardness was measured by a Leitz-Durimet microhardness tester with a $1 \mathrm{~kg}$ load applied for $15 \mathrm{~s}$. Compression tests were performed on cylindrical samples of $6 \mathrm{~mm}$ diameter and $9 \mathrm{~mm}$ length using a $250 \mathrm{kN}$ INSTRON universal testing machine at room temperature. Part densities were determined using the Archimedes method in ethanol.

\section{Results}

\subsection{Density}

The material being produced is novel with an unknown and difficult to determine theoretical full density (TD). The difficulty arises from the different constituents and even phases of the starting material $\left(\alpha^{\prime}-\mathrm{Ti}, \mathrm{Mo}\right.$, and $\left.\mathrm{Mo}_{2} \mathrm{C}\right)$ and the final product $(\beta$ (Ti,Mo), TiC, and trace $\alpha$-Ti, Mo and $\mathrm{Mo}_{2} \mathrm{C}$ ). A simple weighted average of the densities of $\alpha-\mathrm{Ti}, \mathrm{Mo}$ and $\mathrm{Mo}_{2} \mathrm{C}$ results in a density of $5.083 \mathrm{~g} / \mathrm{cm}^{3}$, but this results in calculated part densities $<96 \%$. This does not correspond to the cross-section images, in which no pores could be detected for select parameter combinations. Other calculation routes, including determining the mass per unit cell of a $\beta$-Ti10Mo alloy based on the lattice parameter found in [13], or a weighted average between $\alpha$-Ti and Ti15Mo, yielded equally unrealistic values $\left(5.021 \mathrm{~g} / \mathrm{cm}^{3}\right.$ and $4.839 \mathrm{~g} / \mathrm{cm}^{3}$ resp.). Therefore, $100 \%$ TD was equated to $4.822 \mathrm{~g} / \mathrm{cm}^{3}$, the highest measured density (sample $2 \mathrm{X}$ in Fig. 3), for which no porosity was detected by SEM.

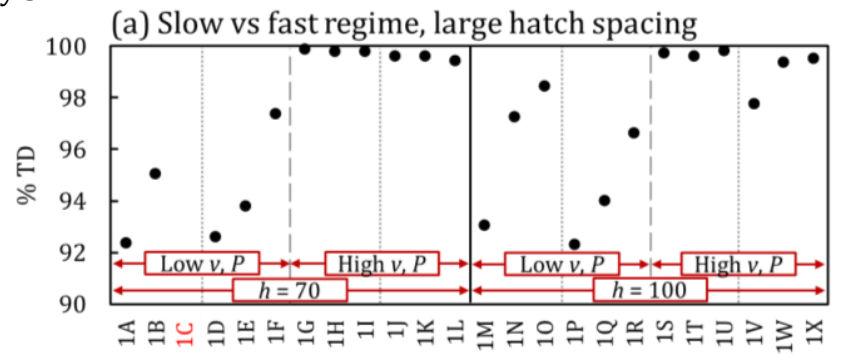

(b) $\mathrm{E}=80 \mathrm{~J} / \mathrm{mm}^{3}$, No remelting vs remelting

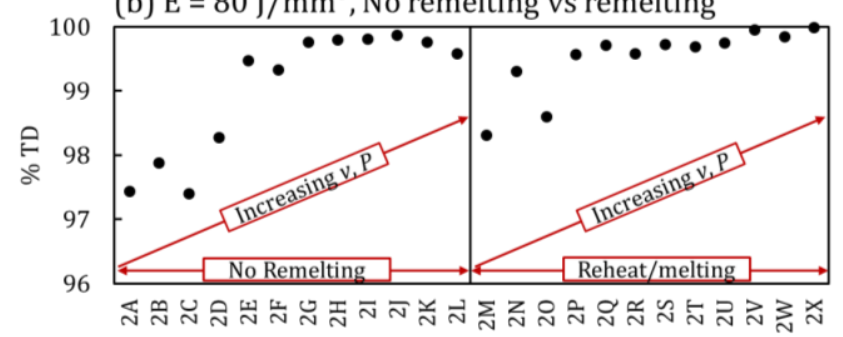

(c) High layer thickness, Small hatch spacing

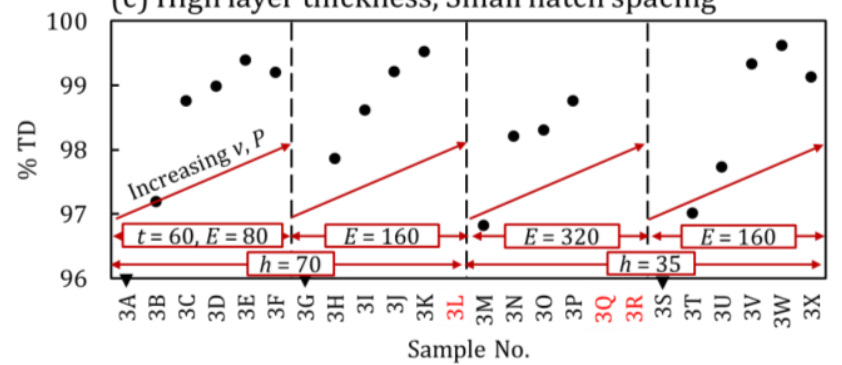

Figure 3. Density evolution as a function of the process parameters. Notice the scale difference between (a) and (b), (c). Unless indicated otherwise, $t$ $=30 \mu \mathrm{m}$ and $h=70 \mu \mathrm{m}$. Failed samples are marked in red.

In Fig. 3(a), a low $v$ - $P$ regime ('Low $v, P^{\prime}$ in Fig. 1) is compared to a high $v$ - $P$ regime ('High $v, P$ ' in Fig. 1), both based around parameter sets that are known to lead to high density for Ti6Al4V [6]. High densities $>99 \%$ are obtained across the entire high $v, P$ regime. By contrast, using a low $v-P$ combination leads to significantly lower densities, even though the energy density covered by both ranges is similar. A similar conclusion can be drawn from Fig. 3(b), where the density increases with increasing $v$ and $P$ (along the $P / v=0.17 \mathrm{~J} / \mathrm{mm}$ line in Fig. 2), and in Fig. 3(c), where the density increases with increasing $v$ and $P$ (along the $P / v$ $=0.34 \mathrm{~J} / \mathrm{mm}$ line in Fig. 2 for $3 \mathrm{~A}$ to $3 \mathrm{R}$ and along the $P / v=0.17$ $\mathrm{J} / \mathrm{mm}$ line in Fig. 2 for $3 \mathrm{~S}$ to $3 \mathrm{X}$ ). Note the different scale on the $\mathrm{y}-$ axis of Fig. 3(a), (b) and (c). In the low $v$-P regime, the density does increase with increasing $P(1 \mathrm{~A}$ to $1 \mathrm{C}, 1 \mathrm{D}$ to $1 \mathrm{~F}, 1 \mathrm{M}$ to $10,1 \mathrm{P}$ to $1 \mathrm{R})$.

Increasing $h$ from $70 \mu \mathrm{m}$ to $100 \mu \mathrm{m}$ did not lead to significant differences, except for the $v=1600 \mathrm{~mm} / \mathrm{s}$ and $P=250 \mathrm{~W}$ combination (sample 1V) that produced a narrow melt pool and consequently lack of fusion between adjacent scan tracks. On the other hand, reducing the hatch spacing from $70 \mu \mathrm{m}$ to $35 \mu \mathrm{m}$ (Fig. $3(c)$ ), effectively doubling the energy density $E$, increased the density for low $P$ and $v$ (sample $3 \mathrm{G}$ vs $3 \mathrm{M}$ ), but led to instabilities and premature build failure when using higher $P$ and $v$ (3Q and 3R). Also visible in Fig. 3(c), the layer thickness could be doubled from $30 \mu \mathrm{m}$ to $60 \mu \mathrm{m}$ (compare samples 3A-3F with 3G-3L) without a significant loss in density. It even allowed the highest $P$ $v$ combination to build successfully while it failed for a $30 \mu \mathrm{m}$ layer thickness ( $3 \mathrm{~F}$ vs $3 \mathrm{~L})$.

From Fig. 3(b), remelting each layer with $P=50 \mathrm{~W}, v=250 \mathrm{~mm} / \mathrm{s}$ and $h=105 \mu \mathrm{m}$ parameters increased the density for low $v$ - $P$ parts, of which the density without remelting was $<99 \%$. If remelting had 
a significant effect on the density $>99 \%$ as in [14], it was outside the accuracy of the Archimedes method.

\subsection{Microstructure}

Fig. 4 represents the microstructural control that can be exercised through variation of the process parameters during SLM of $\mathrm{Ti}+6.5 \mathrm{Mo}+3.5 \mathrm{Mo}_{2} \mathrm{C}$. On the mesoscale, using a low $P-v$ combination leaves residual unmolten or partially molten Mo and $\mathrm{Mo}_{2} \mathrm{C}$ particles (white regions in Fig. 4(a)) since Mo and $\mathrm{Mo}_{2} \mathrm{C}$ respectively melt at $2623^{\circ} \mathrm{C}$ and $2687^{\circ} \mathrm{C}$, compared to $1668^{\circ} \mathrm{C}$ for Ti. Moreover, the dissolved Mo is unevenly distributed in the matrix, evident from the darker (Mo poor/C rich) and lighter (Mo rich) streaks in the side view, a solidified remnant of the melt pool flow. These parameter sets were also prone to more porosity, as discussed earlier. This microstructure corresponds to the diffraction spectrum in Fig. 5(a). The spectrum shows that there is a significant amount of $\alpha$ phase present. By contrast, a higher $P-\nu$ combination as in Fig. 4(b) almost completely dissolves all Mo and $\mathrm{Mo}_{2} \mathrm{C}$ particles. This corresponds to the XRD spectrum in Fig. 5(b). Compared to spectrum 5(a), the $\alpha$ peaks are much smaller, the $\beta$ phase is dominant, and a more pronounced TiC peak at $2 \theta=61^{\circ}$.

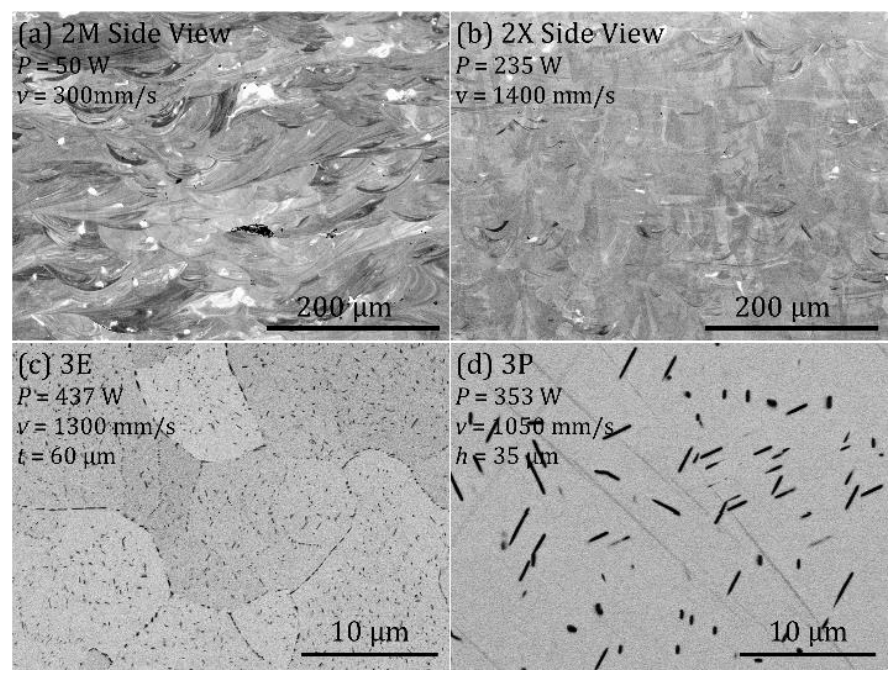

Figure 4. Microstructures obtained after SLM of $\mathrm{Ti}+6.5 \mathrm{Mo}+3.5 \mathrm{Mo}_{2} \mathrm{C}$. (a) Inhomogeneous distribution and incomplete dissolution of $\mathrm{Mo} / \mathrm{Mo}_{2} \mathrm{C}$ using low powers. (b) Homogeneous matrix using higher powers. (c) Fine, homogeneously dispersed precipitates using moderate energy inputs. (d) Coarsened TiC precipitates (black) using high energy inputs.

On the microscale, the desired homogeneous dispersion of fine TiC precipitates is the result of using a moderate to high energy input in the high $P-v$ region. This is shown in Fig. 4(c) where a very high laser power is balanced by doubling the layer thickness. All precipitates are submicrometer in size. They form necklaces along the grain boundaries and are dispersed throughout the interior of the grains. Lastly, as Fig. 4(d) illustrates, the TiC is severely coarsened when using an excessive amount of energy, here achieved by reducing $h$ from $70 \mu \mathrm{m}$ to $35 \mu \mathrm{m}$. The TiC in this work resembles a whisker shape rather than a platelet, as was previously reported in literature $[2,10,11]$. With widths $<200 \mathrm{~nm}$ but up to several micrometers in length, the origin of the whisker shape found in this work is unclear but subject of future work. A coarser TiC size for higher energy inputs was also reported in [9], though not to this extent.

\subsection{Heat Treatment}

Quenching during the SLM process results in a near fully $\beta$ phase metastable matrix. Upon heat treatment, alloy elements trapped in supersaturation will diffuse and be redistributed among both $\alpha$ and $\beta$ phase. This is evident from the diffraction spectra in Fig. 5(c) to 5 (e). Aging at $400^{\circ} \mathrm{C}$ (Fig. 5(c)) and $500^{\circ} \mathrm{C}$ (Fig. 5(d)) did not lead to significant changes in the microstructure or phase composition, but there is a significant formation of $\alpha$ phase when aging at $600^{\circ} \mathrm{C}$ (Fig. 5(e)). Thermomechanical Analysis, not shown here, indicate that this happens at $520^{\circ} \mathrm{C}$. Not only do the $\alpha$ peaks become much more prominent after aging at $600^{\circ} \mathrm{C}$, there is also a small shift in all peak locations due to the solute element redistribution between the $\alpha$ and $\beta$ phase.

The $\alpha$ phase fraction evolves towards equilibrium during aging but declines again at higher temperatures since $\beta$ is the high temperature stable phase. This decline is visible comparing Fig. $6(\mathrm{a})$ to $6(\mathrm{~b})$, and quantified based on pixel greyscale value in Fig. $6(c)$, showing a clear decrease in $\alpha$ phase content and coarsening of the microstructure with increasing temperature reached during heat treatment between $750^{\circ} \mathrm{C}$ and $850^{\circ} \mathrm{C}$. At $750^{\circ} \mathrm{C}$, the microstructure consists of a fine lamellar mixture of $\alpha$ and $\beta$ phase. At higher temperatures, the $\alpha$ phase, decreasing in content, becomes a dispersion of coarser plates. With increasing temperature, the TiC fraction increases from $0.15 \mathrm{vol} \% \approx \approx \mathrm{wt} \%$ for this material) at $750^{\circ} \mathrm{C}$ to $0.78 \mathrm{vol} \%$ at $850^{\circ} \mathrm{C}$, close to the $1.03 \mathrm{wt} \%$ theoretically obtained at $100 \%$ completion of the intended in situ reaction. Comparing Fig. 6(b) with Fig. 4(c), the TiC particles are fewer in number but larger.

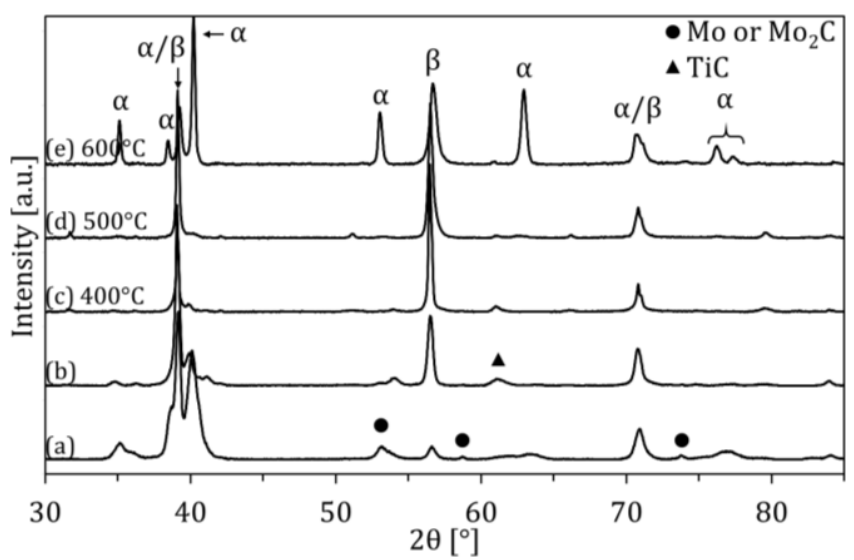

Figure 5. Diffraction spectra for (a) $2 \mathrm{~A}$, built with low power and speed, (b) $2 \mathrm{~L}$, built with higher power and speed, and the aging response $(1 \mathrm{~h}$, air cooling) at (c) $400^{\circ} \mathrm{C}$, (d) $500^{\circ} \mathrm{C}$ and (e) $600^{\circ} \mathrm{C}$. The heat treatments were applied to samples built with the same parameters as $2 \mathrm{~L}$.

\subsection{Mechanical Properties}

The microstructural control that could be enforced through variation of the process parameters as well as post-process heat treatment also leads to a range in obtainable hardness between $350 \mathrm{HV}$ and $550 \mathrm{HV}$. In the as-built state, low $P-v$ combinations that lead to an incomplete dissolution of $\mathrm{Mo}$ and $\mathrm{Mo}_{2} \mathrm{C}$ also lead to a lower hardness around $350 \mathrm{HV}$, compared to $450 \mathrm{HV}$ or above for higher $P-v$ combinations with the same $P / v$ ratio. The maximum hardness of $555 \pm 11 \mathrm{HV}$ was achieved using $P=300 \mathrm{~W}, v=1300$ $\mathrm{mm} / \mathrm{s}, h=50 \mu \mathrm{m}, t=30 \mu \mathrm{m}, E=154 \mathrm{~J} / \mathrm{mm}^{3}$. Even though the maximum theoretical TiC content in this work is only $1.03 \mathrm{wt} \%$, this is similar to the $570 \mathrm{HV}$ obtained in [2] by adding $12.5 \mathrm{wt} \%$ TiC. Using an excessive energy input by using a small $h$, such as for sample 3P shown in Fig. 4(d), leads to a significantly softer material than that produced with similar $P$ and $v$ but a larger $h$.

Aging at $400^{\circ} \mathrm{C}$ or $500^{\circ} \mathrm{C}$ does not significantly change the hardness, but the precipitation of $\alpha$ phase during aging at $600^{\circ} \mathrm{C}$ significantly softens the material (Fig 7(a)). Typically, the $\alpha$ phase is stronger than the $\beta$ phase and a homogeneous dispersion of small $\alpha$ laths has been shown to increase the hardness in aged 
Ti6Al4V+10Mo from $338 \mathrm{HV}$ to $468 \mathrm{HV}$ [7]. The hardness decrease in this work indicates that solid solution hardening contributes significantly to the strengthening, in addition to the $\mathrm{TiC}$ precipitates. Annealing treatments between $750^{\circ} \mathrm{C}$ and $850^{\circ} \mathrm{C}$ further softened the material to $340 \pm 5 \mathrm{HV}$, similar to heat treated Ti6Al4V+10Mo (338 \pm 6 HV) [7].

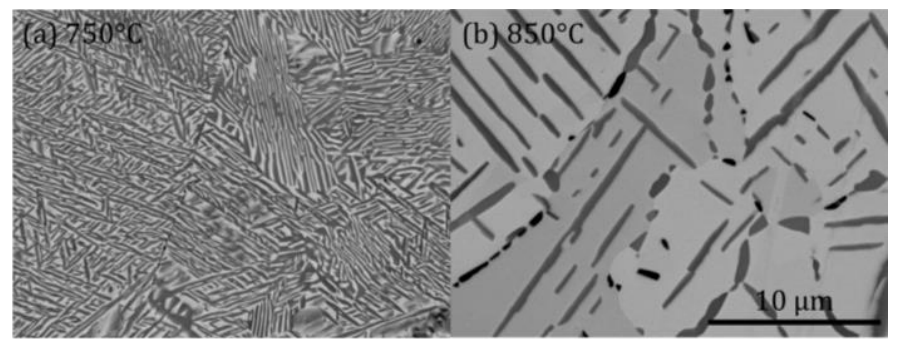

(c) $\alpha(\bullet)$ and TiC ( $\square$ ) fraction

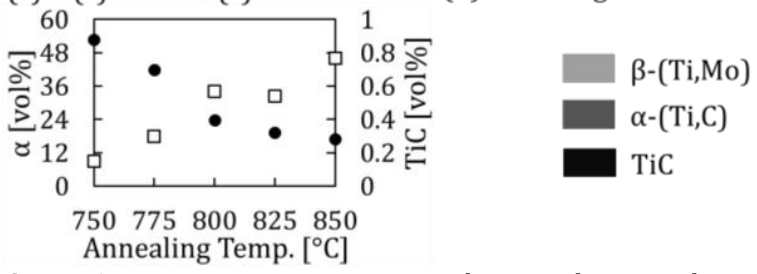

Figure 6. Microstructure coarsening during subtransus heat treatment (1h, water quench) at (a) $750^{\circ} \mathrm{C}$ to (b) $850^{\circ} \mathrm{C}$. (c): based on the grey-scale value (d), the $\alpha$ fraction (vol\%) decreases while more TiC is formed. (a)

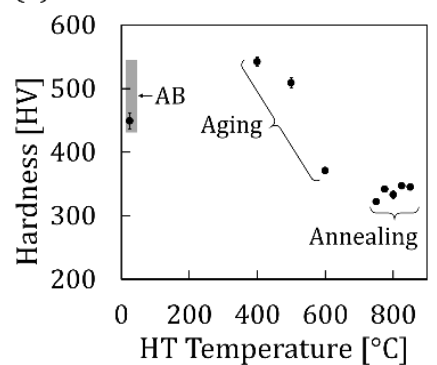

(b)

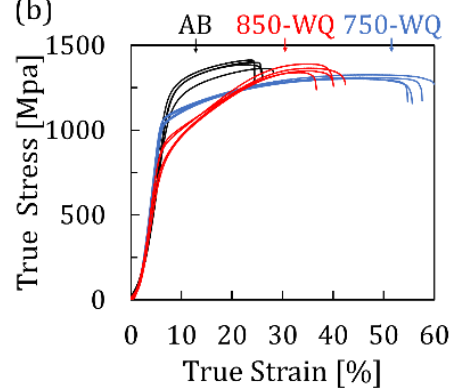

Figure 7. (a) Hardness vs. heat treatment temperature. The hardness drop between $500^{\circ} \mathrm{C}$ and $600^{\circ} \mathrm{C}$ corresponds to the formation of $\alpha$ phase. (b) Compressive stress-strain curves for as-built material (AB) and material annealed at $750^{\circ} \mathrm{C}$ and $850^{\circ} \mathrm{C}$ followed by water quenching (WQ).

Although the compressive stress-strain curves in Fig 7(b) were obtained without an extensometer thus resulting in inaccurate strain data, it is clear that the ductility of the as-built (AB) material can be greatly improved by an annealing heat treatment. A relative improvement of $85 \%$ was obtained when annealing at $750^{\circ} \mathrm{C}$ at a minor reduction in compressive yield stress $\left(\sigma_{0.2,750^{\circ} \mathrm{C}}=1075 \pm 14\right.$ $\mathrm{MPa})$ compared to the as-built state $\left(\sigma_{0.2, \mathrm{AB}}=1164 \pm 37 \mathrm{MPa}\right)$. Heat treating at $850^{\circ} \mathrm{C}$ resulted in the lowest yield stress $\left(\sigma_{0.2,850^{\circ} \mathrm{C}}=812\right.$ $\pm 59 \mathrm{MPa}$ ) and a higher ductility than the AB material, but lower than that of material annealed at $750^{\circ} \mathrm{C}$. It is possible that the coarsened, undeformable $\mathrm{TiC}$ precipitates in the material annealed at $850^{\circ} \mathrm{C}$ impede plastic flow of the surrounding matrix, causing voids to initiate at the matrix-particle interface that eventually lead to failure. This however is still unclear and subject of future work. The ultimate compressive stress did not change greatly after heat treatment with $\sigma_{U C S, A B}=1392 \pm 21 \mathrm{MPa}, \sigma_{U C S, 750^{\circ} \mathrm{C}}=1313 \pm 10 \mathrm{MPa}$, and $\sigma_{\mathrm{UCS}, 850^{\circ} \mathrm{C}}=1362 \pm 22 \mathrm{MPa}$.

\section{Conclusions}

After dissolving $\mathrm{Mo}$ and $\mathrm{Mo}_{2} \mathrm{C}$ particles, density increases and full density is obtained with increasing laser power $P$ and scan speed $v$, eventually resulting in a homogenously alloyed $\beta$-(Ti,Mo) matrix with a fine dispersion of TiC whiskers. In contrast, there are more unmelted particles and a heterogeneous distribution of Mo in the Ti matrix when using low $P-v$ combinations. In the as-built condition, the hardness of up to $550 \mathrm{HV}$ exceeds that of SLM'ed Ti6Al4V (400 HV). Due to supersaturation of C in the matrix, the material is strong $\left(\sigma_{0.2, \mathrm{AB}}=1164 \pm 37 \mathrm{MPa}\right)$ but has a limited deformability. During post-process heat treatment, the TiC plates coarsen while $\alpha$ laths form. This leads to a slightly lower strength but can nearly double the ductility.

This work demonstrates that the microstructure and mechanical properties of in situ formed metal matrix composites can be controlled by variation of the SLM process parameters and postprocess heat treatment. The conclusions are generally applicable to similar material systems in which a powder is alloyed with particles with a higher melting point.

\section{Acknowledgements}

This work was supported by the Flemish Agency for Innovation by Science and Technology (IWT) under Strategic Basic Research (SBO) project "MultiMet", Belgium. This work was partially performed under the auspices of the U.S. Department of Energy by Lawrence Livermore National Laboratory under Contract No. DEAC52-07NA27344.

\section{References}

[1] Gu, D.D., Meiners, W., Wissenbach, K., Poprawe, R. 2012, Laser additive manufacturing of metallic components: materials, processes and mechanisms, Int. Mater. Rev. 57:133-164.

[2] Gu, D.D., Meng, G.B., Li, C., Meiners, W., Poprawe, R., 2012, Selective laser melting of $\mathrm{TiC} / \mathrm{Ti}$ bulk nanocomposites: Influence of nanoscale reinforcement, Scr. Mater. 67:185-188

[3] Dadbakhsh, S., Hao, L., Jerrard, P.G.E., Zhang, D.Z., 2012, Experimental investigation on selective laser melting behaviour and processing windows of in situ reacted $\mathrm{Al} / \mathrm{Fe} 203$ powder mixture, Powder Technol. 231:112-121.

[4] Hua, T., Jing, C., Fengying, Z., Xin, L., Weidong, H., 2009, Microstructure and Mechanical Properties of Laser Solid Formed Ti-6Al-4V from Blended Elemental Powders, Rare Met. Mater. Eng. 38:574-578.

[5] Almeida, A., Gupta, D., Loable, C., Vilar, R., 2012, Laser-assisted synthesis of TiMo alloys for biomedical applications, Mater. Sci. Eng. C. 32:1190-1195.

[6] Vrancken, B., Thijs, L., Kruth, J.-P., Van Humbeeck, J., 2012, Heat treatment of Ti6Al4V produced by Selective Laser Melting: Microstructure and mechanical properties, J. Alloys Compd. 541:177-185.

[7] Vrancken, B., Thijs, L., Kruth, J.-P., Van Humbeeck, J., 2014, Microstructure and mechanical properties of a novel $\beta$ titanium metallic composite by selective laser melting, Acta Mater. 68:150-158.

[8] Gu, D., Hagedorn, Y.-C., Meiners, W., Wissenbach, K., Poprawe, R., 2011, Selective Laser Melting of in-situ TiC/Ti5Si3 composites with novel reinforcement architecture and elevated performance, Surf. Coatings Technol. 205:3285-3292.

[9] Gu, D., Wang, H., Zhang, G., 2014, Selective Laser Melting Additive Manufacturing of Ti-Based Nanocomposites: The Role of Nanopowder, Metall. Mater. Trans. A. 45:464-476.

[10] Liu, D., Zhang, S.Q., Li, A., Wang, H.M., 2009, Microstructure and tensile properties of laser melting deposited TiC/TA15 titanium matrix composites, J. Alloys Compd. 485:156-162.

[11] Mahamood, R.M., Akinlabi, E.T., Shukla, M., Pityana, S., 2013, Scanning velocity influence on microstructure, microhardness and wear resistance performance of laser deposited Ti6Al4V/TiC composite, Mater. Des. 50:656-666.

[12] Van Vaerenbergh, J., 2008, Process optimisation in Selective Laser Melting, University of Twente.

[13] Predel, B., 1997, Mo-Ti (Molybdenum-Titanium), in: Li-Mg - Nd-Zr, SpringerVerlag, Berlin/Heidelberg, pp. 1-3.

[14] Yasa, E., Deckers, J., Kruth, J.P., 2011, The investigation of the influence of laser re-melting on density, surface quality and microstructure of selective laser melting parts, Rapid Prototyp. J. 17:312-327. 